REVIEW ARTICLE

\title{
An Overview of Reports on Clinical Case Report
}

\author{
*MAW Khan ${ }^{1}$, AS Arif ${ }^{2}$ \\ ${ }^{1}$ Prof. Dr Md Abdul Wohab Khan, Professor, Department of Surgery, AKMMC \\ ${ }^{2}$ Prof. Dr Abdus Salam Arif, Professor \& Head, Department of surgery, AKMMC \\ *Corresponding Author \\ Date of submission: 22 February 2015 Date of submission: 7 November 2015
}

\begin{abstract}
Case reports represent the oldest and most familiar form of medical communication. It is one of the best ways for the beginners to get familiar with scholarly writing. It is the time-honored vehicle for medical teaching. It is also the foundational 'building block' of scientific inquiry. Unfortunately from late 1970s in scientific community there was a tendency to see the case report as least important and a 'second class' publication. The authors tried to find out how this 'fertile seeds' were cultivated and valued by the scientific community. Articles on case reports were collected consecutively by daisy chaining from web and published journals. Many logical arguments are found in favor of encouraging in writing and publishing case reports. There are also issues to be addressed further. Diversified criteria and stylescan be followed. Uniqueness is not the only principle, any information which someone find useful and beneficial in clinical practice can be presented as case report. Facts in a case report can be considered as one of the weakest evidence and should not be considered as anecdotal information. To make others aware of unusual presentationsor complications;case report is the rapid and effective means of communication.
\end{abstract}

Key Words: Case report, evidence based practice

\section{Introduction}

Case reports represent the oldest and most familiar form of medical communication ${ }^{1}$. Case descriptions suggestive of cancers were found in papyrus records in Egypt; as early as $1600 \mathrm{BC}^{2}$. Even before Hippocrates case reports have provided a rich resource for teaching and research in medicine ${ }^{3}$. Sir William Osler encouraged others to record and publish whenever they have made or recorded unusual or original observation ${ }^{4}$. It is one of the best ways for beginners to get familiar with scholarly writing 5 . A case report may not have as much potential impact on the science or practice of health care as randomized controlled trial or other research results. However, it may be the only way to make others in the field aware of unusual presentations or complications. Most importantly it is the timehonored vehicle for teaching others. New syndromes, manifestations, associations, complications, or outcomes are appropriate subjects for case reports, as are typical well-documented examples of known entities that are relevant to a journal's readers ${ }^{6}$.
Case reports are the foundational 'building blocks' of scientific inquiry ${ }^{7}$. Many original observations were first presented as case reports. The discovery of AIDS was founded on the basis of a case report on extensively disseminated Kaposi's sarcoma in a young homosexual man published in the American Journal of Dermato-pathology in 19813.Unfortunatelyfrom late 1970sin scientific community there was a tendency to see the case report as least important and a 'second class' publication ${ }^{1,8}$. In Bangladesh and probably most of the peer reviewed journal all over the world; case reports are published in a separate section, not in the 'original article' sections. The authors tried to find out why a case report was not valued as an original publication or an important source of information in scientific progress. How they are valued in the scientific community was also an inspiring quarry. This article probably will help to focus on the way to answer the questions. 


\section{Methods}

The case report and the articles on case reports were retrieved from web. The articles on case reports in the published journals in different libraries of medical institutes were also reviewed. The case reports and articles written on case reports were selected consecutively. Articles were collected by daisy chaining. Data synthesized and informations were collected and recorded on a predesigned data collection form and checklist. These were developed on the basis of reviewer's checklist for case report of few national and international peer reviewed journals. Suggestions from critical appraisal checklist used in the journal club of different institutes were also taken into account. Some statistical and research methodology text books were also consulted ${ }^{9-11}$.

\section{Results and discussion}

\section{Definitions and Terminologies}

A case may be defined as a happening, an event or an occurrence ${ }^{12}$. A medical case report is 'an article that scientifically describes and interprets an individual case or few cases often written in the form of a detailed story of illness, including the presenting signs and symptoms, diagnostic studies, treatment course and outcome $e^{6,8,13,14}$. Sir William Osler described case reports as a 'scientific observations; carefully documented so that they may be a valuable education and research resource ${ }^{4}$. Usually most of the report consists of a single report often termed as 'clinical case report', 'a medical case report', 'a single patient case report','case report', 'clinical story'and'a single case report'. If more than one, it may be called 'case series', 'case series report', 'time series case report6,15-17.

\section{Case Report and Case Series}

There is no consensus on defining the demarcation between case report and case series. Case report is the detailed description of case(s) and case series is the cumulative group result of a number of cases $^{18,19}$. Both are descriptive and observational research design but case report is much towards qualitative and case series is more to describe the findings quantitavely ${ }^{20}$. There is no agreed minimum or maximum number; some accept at least three as case series ${ }^{21}$ and others acceptten or less in case report ${ }^{15}$. In a study on case report taken from several prestigious journals, Abu-Zidan et a ${ }^{18}$ reported that more than $52 \%$ case reports have case number less than 5 on the other hand $63 \%$ of case series had case number 10 or less with a median number of seven per series.

\section{Case Report and Study Design}

Case report is a descriptive study design with 'in depth and naturalistic'analysis. In that sense it has got similarities with qualitative research. In general a case report is retrospectiveeas it is not a part of planned or predesigned research project ${ }^{6,17,22}$. It can be experimental and prospective when the author plan the patient care ahead of time, as it was done in ligating PDA on a patient in $1939^{23}$ and in doing a parathyroid adenectomy using endoscopic technique in BSMMU in $2007^{24}$; it is then called 'a case study' ${ }^{8}$.'Time series case report' is one of the prospective designs as used by some to generate a hypothesis where the clinician takes data several times before and after the intervention ${ }^{25}$. One of the time series design is 'AB case report' where at least three measurements is taken to avoid inaccurate measurement both before (phase A) and during the care(phase B) ${ }^{26,27}$.

\section{Place of Case Report in Publication}

The number of case report and its acceptance as publication is increasing. Sorinolaet $\mathrm{a}^{28}$ found about 240,000 case report on Medline between 1997 and 2002. In another review it was shown that case report constitute about $7 \%$ of medical journal publication of which $2 \%$ were published as original article. It was also noted that most (72\%)of the single case report was published by the specialists ${ }^{29}$. Case report is considered as the most popular form of medical communication. In a study it was shown that $19 \%$ to $35 \%$ of patients presenting to GP with unexplained symptoms and apprehending that something is missing. A case report may highlight a new way to explain thosesymptoms ${ }^{30}$. Many original observations were detected first and reported as case report. So it should not be ignored or appreciated as a second class publication ${ }^{1}$. Many peer reviewed journal have a 'Case report' section. Various formatsare used,such as 'Clinical case conference', 'technical report', 'letter to the editor' 'lesson of the month' 
52 AKMMC J 2016: 7(1)

and'Evidence based case report ${ }^{8,31}$. There are also Journals to publish case reports as 'core publications' 32 .

\section{Case Reports as Citation}

Usually case report has got a low citation value. It isnot frequently cited and is 'less often quoted' than other type of articles. Its publication tends to be declining in journals with high impact. It is considered that these are written by less experienced younger clinician.Although seem less important but the close and regular involvement of the younger clinician than their seniors can be a great environment for good case studies ${ }^{8,33,34}$.

\section{Case Report and Evidencebased Medicine}

Traditionally case report is considered as anecdotal information due to its small sample size. Still it is an 'amusing and interesting' account of a particular incident or event ${ }^{35-37}$. Important and detailed information of a single incidence for clinical practice may be missed or beyond the scope of larger studies but can bediscussed in case report ${ }^{34,38}$. Case report can help and guide in clinical decision making process ${ }^{39}$. The experiences on a case should not change the way of an established management of any diseases but should create a desire to rethink on it $^{17,40-45}$. The controversy of scientific value of a case report has been diminishing and the demand and importance of its publication increasing from the late $1990 \mathrm{~s}^{8,32}$. Pearson ${ }^{46}$ summarized the reports from literatures; to rank thearticles as evidences. Case report was not in the list in most of thehierarchy schemes. Those who considered case report as evidence; it was placed at the lowest step of the ladder ${ }^{48}$.

Report on cases was the only basis of clinical medicine for many centuries and they can still contribute to our knowledge and understanding 49,50 . Case report for alerting the practitioners to possible new reactionsis one of the vital safety points for the treatment process. The case report serves to describe the basic needs of medical science for its real progress $^{8}$. Many scientific communitiesare considering that the case report is not anecdotal information. It may be the 'weakest' but first line of evidences in health care $2,6,17,33,51$.
MAW Khan, AS Arif

\section{Medical Education and Case Report}

Medicine is the subject which should be learnt in workplace. Case report has been used for many years as an important means for educating students. Case reports provide a rich resource for teaching and research in medicine ${ }^{3,47,52}$. 'A case report, if prepared properly, is a valuable educational device to describe clinical syndrome, association, reaction, or treatment. If a report advances basic understanding of a disorder, increases clinical skill, or suggests useful research, it is worthy'53. Case based educational articles published in many journals from ground round presentations, case of the month and clinicopathological conferences are one of the important approaches for educating the medical practioners ${ }^{17,40-46}$. Case report isvaluable when it describesusual or unique conditionsand presents an event that is new or clinically educational ${ }^{33,54}$. It is a useful resource to highlight on key learning points for the practioners on rare conditions ${ }^{39}$. A case report is more valuable in learning benefit and risks on newly emerging or traditional (accupuncture) therapeutic speciality ${ }^{49}$.

\section{Reasons to Publish a Case Report}

A case report can be the source of new knowledge if it describespreviously unknown syndrome or disease, unreported association of two distinct diseases, a previously unreported observation in a known case or an unusual or exceptional pattern of presentation of a known diseaseand a previously unrecognized therapeutic adverse or beneficial effect of an intervention $5,7,38,51,55,56$. New observation or explanation of a finding to elucidate the mechanism of disease or to offer a new insight on pathogenesis or a challenging differential diagnosis can be important attraction of reporting a case $\mathrm{c}^{47,57}$. Clinically important hazards or potential problems associated with the use of diagnostic or therapeutic devices or materials, mistake in diagnosis and causes and consequences of those can be a matter of discussion in a case report ${ }^{58}$. To demonstrate a manifestation, finding or feature more clearly with a new technology or technique can be described in acase report ${ }^{59}$. To illustrate, support or to point out anew hypothesis can be a theme for reporting a case $^{47}$. Care in an unusual clinical setting can be described in the form of a case report ${ }^{17}$. The 
An Overview of Reports on Clinical Case Report

'typical or classical'case can be reported to summarize and synthesize existing knowledge for educational purposes ${ }^{33,47,51}$.

\section{Case Report as a Foundation of Research}

For a rare and new clinical events case report is the main and principal means of surveillance ${ }^{31}$. Report on cases can provide a data or information to generate questions in the clinician's mind ${ }^{8}$. Despite the limitation of case reports, these are useful to generate new hypothesis for future large scale clinical trials ${ }^{17,40-46}$. It is considered as the foundation of experimental research. It can contribute to medical science in two ways; as a source of new knowledge and in medical education and audit ${ }^{6,8,47,56,60-64}$. Useful information and evidences also can be synthesized by doing meta-analysis of case reports ${ }^{7}$.

\section{Pitfalls in Quality of Case Report}

Although many of the case reports are academically worthy they cannot be accepted due to poor writing qualityand improper format ${ }^{6}$. This may result from lack of experience in scientific writing. One of the common causes of poor quality may results from poor documentation. Sometimes common or widely reported cases are thought to be raredue to poor literature review. Inadequate care or improper management resulting from misunderstanding of pathophysiology may result in an event seems to be unique but cannot be the thing to be published. Quality of a case report may be compromised as a result of inadequate focusing on primary message. A case may be difficultto understand by the readers due to complex or unusual illustrations. Useful information will be weakly supported due to poor use of references ${ }^{47}$.

\section{Elements of a Case Report}

In most of the articles it is found that it the shortest of all publications. The constant components are introduction, case summary, discussion and references ${ }^{47}$.

\section{Weaknesses and Strengths of the Case Report}

The major weakness is its small sample size. An exceptional case cannot be generalized. Report on cases can provide a data or information to generate research questions and hypothesis in the clinicians' mind but should not be considered as established evidence. A case report is prepared usually retrospectively and may not be based on systemic observation so there is a chance of missing relevant information. More importantly the associations may have their own explanations. The dangerous aspect is that there may be emphasis on the bizarre element or focusing on a misleading item 8,55 . The design pitfall should be kept in mind such as inadequate description of the case. The observation may be biased with subjective variation ${ }^{31}$. Confidentiality may be difficult to preserve in an isolated case report $^{8}$.

There are usually little or no ethical issues in case report. Someone can report a case and learn from mistakes and this is the only way to have a 'natural experiment' to invent new things ${ }^{8}$. One advantages of case report from authors view is its low volume and cost involvement. The other favorable point is its structural flexibility to express the finding and analysis ${ }^{33}$. The strength of case report is that it can be published quickly to notice and warn on unusual events to the clinicians ${ }^{54,65}$.

\section{Limitations}

The authors could not go through all the relevant literature as the number of publications is so many. It was also difficult to manage time to look at every detail. There are numerous publications on each aspect pointed out and the authors had selected only few to refer. Only on medical case reporting was discussed and as a result other aspects could not be analyzed.

\section{Conclusion}

The importance of writing case reports are gaining attention day by day. Information in case report should not have an impact on practice of health care as other research articles. It should be used to make others aware of unusual presentationsor complications. It is a time honored method forteaching others.Newsyndromes, manifestations, associations,complications, or outcomes are most appropriate subjects for publishing a casereports. 


\section{References}

1. American College of Physicians (ACP), Writing a Clinical Vignette (Case Report) Abstract; 2013 viewed on $04 / 04 / 2013$

f r o m http://www.acponline.org/residents_fellows/competition s/ abstract/ prepare/clinvin abs.htm.

2. Dib EG, Kidd MR and Saltman DC. Case reports and the fight against cancer. Journal of Medical Case Reports 2008,2:39 http:// www.jmedicalcasereports.com/ content $/ 2 / 1 / 39$.

3. McCarthy LH and Reilly KEH, How to write a case report. Family Medicine, March 2000; 32(3): 190-195.

4. Coccia CT, Ausman JI. Is a case report an anecdote? In defense of personal observations in medicine.SurgNeurol 1987; 28:111-13.

5. Iles RL, Piepho RW. Presenting and publishing case reports. J ClinPharmacol.1996; 36:573-579.

6. Gopikrishna V, A report on case reports, J Conserv Dent. 2010 ; 13(4): 265-271.

7. Jenicek M. Clinical Case Reporting in Evidence-Based Medicine. Oxford: Butterworth-Heinemann; 1999:117.

8. Nissen $\mathrm{T}$ and Wynn $\mathrm{R}$. The recent history of the clinical case report: a narrative review. J R Soc Med Sh Rep 2012; 3:87. DOI 10.1258/shorts.2012.012046.

9. Azad AK 2006, Type and design of study in planning and doing research, pp. 20-57.

10. Khanam ST 1996, Research methodology, basic concepts, Dhaka.

11. Mahajan BK 1997, Methods in biostatistics, ed. 6th, Jaypee Brothers, New Delhi

12. Tolwani A. Research model designs. In: Nordness R, ed. Epidemiology and Biostatistics Secrets. Philadelphia: Mosby Elsevier, 2006.

13. Venes D. Taber's Cyclopedic Medical Dictionary. 21st edn. Philadelphia: F. A. Davis Company, 2009.

14. Case Report, Himmelfarb Health Sciences Library, the George Washington University, Nov 2011, mretrived on 13/04/2013 from http:// www.gwumc.edu/library/ tutorials/studydesign101/ casereports.html.

15. Fletcher RH, Fletcher SW. Clinical research in general medical journals. A 30-year perspective. N Engl J Med. 1979; 301:180-3.

16. Jenicek M. Clinical case reporting in evidence-based medicine.2nd ed. Oxford: Butterworth-Heinemann; 2001.

17. Green BN and Johnson CD, Writing Patient Case Reports for Peer-reviewed Journals: Secrets of the Trade, Journal of Sports Chiropractic \& Rehabilitation 2000; 14(3): 51.
18. Abu-Zidan FM, Abbas AK, Hefny AF. Clinical "case series": a concept analysis. African Health Sciences 2012; (4): 557 - 562.

19. Grimes DA, Schulz KF. Descriptive studies: what they can and cannot do. Lancet. 2002; 359: 145- 149.

20. Patterson PD, Weaver M, Clark S, Yealy DM. Case reports and case series in pre-hospital emergency care research. Emerg Med J 2010; 27: 807-809.

21. Hennekens $\mathrm{CH}$, Buring JE, Mayrent SL, eds. Epidemiology in Medicine. First edition, USA: Little, Brown and company Boston/Toronto; 1987.

22. Keating JC. Towards a philosophy of the science of chiropractic: a primer for clinicians. Stockton, CA: Stockton Foundation for Chiropractic Research; 1992:199-222.

23. Anwar-ul-haq, Ubaidullah ,Samiullah, Javeria, Neelofar, Abbasi MZ, Surgical ligation of patent ductusarteriosus in a noncardiac Surgical centre. J Ayub Med Coll 2009;21(3): 25-28.

24. Aziz MM, Khan AW, Uddin MF, Hasnat MA, Kader MA, Chowdhury AJ, Chowdhury NA. Endoscopic parathyroidectomy: A new Approach. Mymensingh Med J 2010 Jul: 19(3): 442-446.

25. Keating JC, Giljum K, Menke M, Lonczak RS, Meeker WC. Toward an experimental chiropractic: time series designs. J Manipulative Physiol.Ther. 1985; 8(4):229- 238.

26. Azzaldeen A, Muhamad AH and Watted N. Dental case report for publication; step by step; Indian Journal of Medical Case Reports 2014 Vol.3 (1) January-March, pp. 94-100.

27. Riddoch J. Evaluation of practice. Physiotherapy 1991; 77(9):439-444. From http:// www.physiotherapyjournal.com/ article/ S0031-9406\%2810\%2961299-0/abstract

28. Sorinola O, Olufowobi O, Coomarasamy A and Khan KS. Instructions to authors for case reporting are limited: A review of a core journal list. BMC Medical Education 2004: 4:4 from: http://www.biomedcentral.com/1472-6920/4/4

29. Kljakovic M. Single cases in general practice and general medical journals. Aust. Fam. Physician 2002;31(7):669673. [pub med abstract]

30. Peveler R, Kilkenny L, Kinmonth AL. Medically unexplained physical symptoms in primary care: a comparison of self-report screening questionnaires and clinical opinion. J Psychosom Res. 1997 Mar;42(3):245-52

31. Doherty M 1994. What values case report? Annals of the Rheumatic Diseases. 1994; 53: 1-2. 
32. Rison RA, Kidd MR and Koch CA The CARE (CAseREport)guidelines and thestandardization of case reportsJournal of Medical Case Reports 2013, 7:261http://www.jmedicalcasereports.com/content/7/1/261

33. Agha R, Rosin DR. Time for a new approach to case reports. Int J Surg Case Rep. 2010 May;1(1):1-3.

34. Varras M. Clinical and educational significance of case reports in medicine. OA Case Reports 2012; 1(1):1.

35. Anecdote, Wikipedia, from http:// en.wikipedia.org/ wiki/ Anecdote, last modified on 3 April 2013.

36. Anecdotal evidence, Wikipedia, from http:// en.wikipedia.org/wiki/ Anecdotal_evidence, last modified on 25 February 2013.

37. Dictionary.com, 2013 from http:// dictionary.reference.com/ browse $/$ Anecdote $? \mathrm{r}=75 \& \mathrm{src}=\mathrm{ref} \& \mathrm{ch}=\mathrm{dic}$

38. Kidd $\mathbf{M}$ and Hubbard C. Introducing Journal of Medical Case Reports. Journal of Medical Case Reports 2007, 1:1.from: http://www.jmedicalcasereports.com/content/1/1/1

39. Wong G. Case reports: A helping hand to generalists. Journal of Medical Case Reports 2008, 2:311.

40. Târcoveanu E, Roca M, Mih?escu T. [Writing and publication of a clinical case report].Chirurgia (Bucur). 2011; 106(5):581-4. [Article in Romanian]

41. Pascal RR. Case reports-desideratum or rubbish? Hum Pathol 1985; 16:759.

42. Richtsmeier WJ. Case report. Arch Otolaryngol Head Neck Surg 1993; 119:926.

43. Simpson RJ Jr, Griggs TR. Case reports and medical progress. Perspect. Biol. Med. 1985; 28:402-6.

44. Treasure T. What is the place of the clinical case report in medical publishing? J R Soc. Med 1995; 88:279

45. Friedell MT. The case report. Int. Surg 1973;58:225.

46. Morgan PP. Why case reports? Can Med Assoc J 1985;133:353.

47. Pierson DJ. Case Reports in Respiratory Care, Respir. Care 2004; 49(10):1186 -1194.

48. Association of physicians. Case report, case series and systemic review. QJMed 2002; 95: 195-198.

49. White A, Writing case reports - authors guideline for Acupuncture in medicine, Acupuncture in medicine 2004; 22(2): 83 -86.

50. Wright SM, Kouroukis C. Capturing zebras: what to do with a reportablecase. CMAJ 2000; 163(4):429-431.
51. Vandenbroucke JP. In defense of case reports and case series. AnIntern Med 2001; 134(4):330-334.

52. Fenton JE, Khoo SG, Ahmed I, Ullah I, Shaikh M. Tackling the case report. AurisNasus Larynx. 2004;31:205-207.

53. DeBakey L, DeBakey S. The case report. Guidelines for preparation. Int J Cardiol. 1983; 4(3):357-64.

54. Marone U. Case reports: More than anectodal evidence. J Clinic Case Reports.2012; 2:e111.

55. Hoffman JR. Rethinking case reports, Highlighting the extremely unusual can do more harm than good. WJm, 1999; 170:253.

56. Huth EJ. Writing and publishing in medicine. Baltimore: Lippincott Williams and Wilkins; 1999. pp. 103-10.

57. GhamraZ andStoller JK. Basilar Hyperlucency in a Patient With Emphysema due to Hypocomplementemic Urticarial Vasculitis Syndrome.Respir Care 2003;48(7):697- 699.

58. El-Khatib MF, Kiwan RA, Jamaleddine GW. Buspirone Treatment for Apneustic Breathing in Brain Stem Infarct. Respir Care 2003;48(10):956-958.

59. Manali et al. Endobronchial findings of fibrosingmediastinitis. Resp Care2003;48(1):1038-42.

60. Asgary S. Furcal perforation repair using calcium enriched mixture cement. J Conserv Dent. 2010;13:156-8.

61. Asgary S, Ehsani S. Permanent molar pulpotomy with a new endodontic cement: A case series. J Conserv Dent. 2009;12:31-6.

62. ChakradharRaju RVS, Sathe N, Morisetty P, Veeramachaneni C. Endodontic management of a maxillary first molar with unusual location of second mesiobuccal orifice. J Conserv Dent. 2010;13:162-4.

63. Rachana D, Nadig P, Nadig G. The palatal groove: Application of computed tomography in its detection - A case report. J Conserv Dent. 2007; 10:83-8.

64. Tandri SB. Management of infected radicular cyst by surgical decompression.JConserv Dent. 2010; 13:159-61.

65. Varras M. Clinical and educational significance of case reports in medicine. OA Case Reports 2012; 1(1):1. 